\title{
THERMOMECHANICAL RESPONSES OF FUNCTIONALLY GRADED CYLINDERS
}

\author{
Mehmet Eker', Durmuş Yarımpabuç ${ }^{2}$ \\ ${ }^{I}$ Department of Mechanical Engineering, Tarsus University \\ Tarsus/Mersin, Turkey \\ ${ }^{2}$ Department of Mathematics, Osmaniye Korkut Ata University \\ Osmaniye, Turkey \\ mehmeteker@tarsus.edu.tr,durmusyarimpabuc@osmaniye.edu.tr
}

Received: 17 October 2021; Accepted: 13 December 2021

\begin{abstract}
In this study, thermal and mechanical stresses in hollow thick-walled functionally graded (FG) cylinders is presented under the convection boundary condition. The convective external condition and constant internal temperature in hollow cylinders are investigated. Inhomogeneous material properties produce irregular and two-point linear boundary value problems that are solved numerically by the pseudospectral Chebyshev method. The displacement and thermal stress distributions are examined for two different material couples under particular boundary conditions that are similar to their real engineering applications. Results have demonstrated that the pseudospectral Chebyshev method has low computation costs, high accuracy and ease of implementation and can be easily customized to such engineering problems.
\end{abstract}

MSC 2010: 74B05, 74E05, 74S25

Keywords: functionally graded materials, hollow cylinder, pseudospectral Chebyshev method, thermal stress

\section{Nomenclature}

$a$ inner radius

$b$ outer radius

$k$ thermal conductivity

$\alpha$ thermal expansion coefficient

$h$ thermal convection coefficient

$D$ Chebyshev differentiation matrix

$E$ Young's modulus

$q_{0}$ initial heat generation

$r$ radial coordinate

$u$ radial displacement

$\sigma_{r}$ radial stress $\sigma_{\theta} \quad$ circumferential stress

$\sigma_{z} \quad$ axial stress

$P$ pressure

$T$ temperature distribution

$T_{\infty}$ ambient temperature

$T_{w} \quad$ wall temperature

$Q \quad$ internal heat generation

$\varepsilon_{r} \quad$ radial strain

$\varepsilon_{\theta} \quad$ circumferential strain

$\lambda, \mu$ Lame coefficients

$m_{j}$ inhomogeneity parameters $(j=1,2,3)$ 


\section{Introduction}

Functionally graded materials (FGMs) are innovative composite materials whose thermal and mechanical properties vary smoothly from one surface to the next. They offers many benefits, including better thermal characteristics, increased material strength, improved residual stress distribution, high fracture toughness, and relatively low in plane and transverse stresses. The FGM thick-walled cylinder is widely utilized in many industries for delivering and reserving fluids under pressure and temperature loads, including power/chemical plants, aerospace, biomedical, petroleum, and others. FGMs have been the subject of a substantial amount of research [1].

In the past several decades, functionally graded materials have also played an important role in the design of cylindrical structures. Many of the studies deal with temperature, displacement and stress distribution of functionally graded hollow cylinders with different solution procedures. The solution methods used in the literature can be listed as: the perturbation method [2], the direct method [3], a novel limiting approach [4], generalized Bessel function and Fourier integral [5], Fredholm integral equation [6], a tolerance averaging approach [7], Differential quadrature method [8], representative volume element [9], the multilayer semi-analytical method [10], complementary functions method [11], the direct method and finite element method [12], an approximate method for a cylinder divided into $\mathrm{N}$ layers [13], the non-linear shooting method and the Runge-Kutta fourth-order algorithm [14].

This paper deals with thick-walled hollow cylinders that are graded with two different material couples. Material distribution is assumed to vary an exponential function in the radial direction. Systems of linear ordinary differential equations with variable coefficients have been solved numerically with the pseudospectral Chebyshev method. Differentiation matrices that signify the approximations at grid points play an important role in the implementation of spectral collocation methods [15]. The constructing procedure of Chebyshev differentiation matrices with the help of Chebyshev points (grid points) is found in Fornberg [16] and the implementation for the numerical solution of a convection-diffusion problem in Bazan [17]. The method is used to generate results for the temperature, displacement, and thermal stress distributions.

\section{Mathematical formulation of the problem}

Temperature, displacement and stress analysis of a one-dimensional axisymmetric functionally graded cylindrical body is considered. A thick-walled hollow cylinder subjected to steady-state thermal and mechanic loads is investigated. The modulus of elasticity, heat conduction coefficient, the linear thermal expansion coefficient and Poisson's ratio of the body are assumed to be graded exponentially in the radial direction as follows:

$$
\begin{aligned}
& E(r)=E_{m} e^{\frac{m_{1}(r-a)}{b-a}}, k(r)=k_{m} e^{\frac{m_{2}(r-a)}{b-a}}, \alpha(r)=\alpha_{m} e^{\frac{m_{3}(r-a)}{b-a}}, \\
& v(r)=v_{m} e^{\frac{m_{4}(r-a)}{b-a}}
\end{aligned}
$$


Here, subscript $m, m_{j}, j=1,2,3,4, r, a$ and $b$ represent metal constituents, inhomogeneity parameters, radial coordinates, inner and outer radius, respectively.

Temperature distribution of the FG cylinder in a steady-state condition with internal heat generation is described by the axisymmetric heat conduction equation [18] as follows:

$$
\frac{1}{r}\left[r k(r) T^{\prime}(r)\right]^{\prime}+Q=0
$$

where the prime refers to the derivative with respect to $r$, and $T(r)$ is the temperature in the radial direction. Under the assumption of no internal heat generation, substituting the exponential form of the heat conduction coefficient (1) into Eq. (2) renders the heat conduction equation in the following form:

$$
T^{\prime \prime}+\left(\frac{m_{2}}{b-a}+\frac{1}{r}\right) T^{\prime}=0
$$

with a uniform inner surface temperature and convective outer surface that is exposed to an airstream $\left(h_{o}=20 \mathrm{~W} / \mathrm{m}^{2} \cdot \mathrm{K}\right)$

$$
T(a)=T_{w}, \quad\left[k_{m} \frac{d T}{d r}+h_{o}\left(T-T_{\infty}\right)\right]_{r=b}=0
$$

The governing equation for the stress field of the cylindrical body consists of strain-displacement equations

$$
\varepsilon_{r}=\frac{d u}{d r}, \quad \varepsilon_{\theta}=\frac{u}{r}
$$

stress-strain-temperature relations

$$
\begin{gathered}
\sigma_{r}=(\lambda(r)+2 \mu(r)) \varepsilon_{r}+\lambda \varepsilon_{\theta}-(3 \lambda(r)+2 \mu(r)) \alpha(r) T(r) \\
\sigma_{\theta}=(\lambda(r)+2 \mu(r)) \varepsilon_{\theta}+\lambda(r) \varepsilon_{r}-(3 \lambda(r)+2 \mu(r)) \alpha(r) T(r) \\
\sigma_{z}=\lambda(r)\left(\varepsilon_{r}+\varepsilon_{\theta}\right)+-(3 \lambda(r)+2 \mu(r)) \alpha(r) T(r)
\end{gathered}
$$

and stress equilibrium equation

$$
\frac{d \sigma_{r}}{d r}+\frac{\sigma_{r}-\sigma_{\theta}}{r}=0
$$

Here, $\sigma_{r}, \sigma_{\theta}, \sigma_{z}$ represent the radial, hoop and axial stress, and $\varepsilon_{r}, \varepsilon_{\theta}$ are the strain tensors. Lame coefficients, $\lambda(r)$ and $\mu(r)$ are related to the modulus of elasticity $E(r)$ and Poisson's ratio $v$ in the following way:

$$
\lambda(r)=\frac{v(r) E(r)}{[1+v(r)][1-2 v(r)]}, \mu(r)=\frac{E(r)}{2[1+v(r)]}
$$


Substituting Eqs. (5)-(6) into the equilibrium Eq. (7), by using Lame coefficients (8) with the exponential form of the modulus of elasticity and the linear thermal expansion coefficient (1) renders the linear non-homogeneous ordinary differential equation (ODE) in terms of radial displacement, $u$ as follows:

$$
u^{\prime \prime}+P(r) u^{\prime}+G(r) u=R(r)
$$

where

$$
\begin{gathered}
P(r)=\frac{\lambda^{\prime}+2 \mu^{\prime}}{\lambda+2 \mu}+\frac{1}{r} \\
G(r)=\frac{\lambda^{\prime}}{\lambda+2 \mu} \frac{1}{r}-\frac{1}{r^{2}} \\
R(r)=\alpha e^{m_{3}\left(\frac{r-a}{b-a}\right)}\left[\left(\frac{3 \lambda^{\prime}+2 \mu^{\prime}}{\lambda+2 \mu}+\frac{1+v}{1-v} \frac{m_{3}}{b-a}\right) T+\frac{1+v}{1-v} T^{\prime}\right] .
\end{gathered}
$$

\section{Numerical resolution of the problem}

In the pseudospectral Chebyshev method, a solution is made in the interval determined in the problem. The mesh points that will keep the error to a minimum are selected and the interpolation polynomial at these points is found. In order to obtain high precision solutions by using fewer points in the solution of the problem, Chebyshev Gauss-Lobatto points, which contain a more dense point distribution at the boundary points compared to the midpoints, are preferred. These points are equally spaced on the semicircle in accordance with the equation below.

$$
r_{j}=\cos \left(\frac{j \pi}{n}\right), \quad(j=0,1, \ldots, n)
$$

Since they are projected on the horizontal axis, they form a distribution that is dense at the borders and sparse at the midpoints. Thus, high precision solutions can be obtained with fewer grid points.

The pseudospectral Chebyshev Model is utilized to perform the thermal stress analysis of FG hollow cylinders under the convective boundary condition by referring to the study of Trefethen [15], Fornberg [16] and Gottlieb [19] that depends on discretization of the governing equations (3), (9), (12), (15) with respect to the spatial variable using the pseudospectral Chebyshev method. With regard to collocation points, the first order $(n+1) x(n+1)$ Chebyshev differentiation matrix will be obtained and denoted by D. First-order Chebyshev differentiation matrix $D$ provides highly precise approximation to $u^{\prime}\left(r_{j}\right), T^{\prime}\left(r_{j}\right), u^{\prime \prime}\left(r_{j}\right), T^{\prime \prime}\left(r_{j}\right) \ldots$, simply by multiplying the differential matrix with vector data $u^{\prime}\left(r_{j}\right)=(D u)_{j}, T^{\prime}\left(r_{j}\right)=(D T)_{j}$, 
$u^{\prime \prime}\left(r_{j}\right)=\left(D^{2} u\right)_{j}, T^{\prime \prime}\left(r_{j}\right)=\left(D^{2} T\right)_{j}$ suchlike where $\boldsymbol{u}=\left[u_{0}, \ldots, u_{n}\right]^{T}$ and $\boldsymbol{T}=$ $=\left[T_{0}, \ldots, T_{n}\right]^{T}$ discrete vectors data at positions $r_{j}$.

The computation procedure of the Chebyshev differentiation matrix and codes as an $m$-file can be found in notable references see e.g. [15], where the collocation points $r_{j}$ are numbered from right to left and defined in $[-1,1]$. With a small revision, the method can be implemented to any interval.

The detailed implementation of the method is explained in the study of Trefethen [15] and Bazan [17]. Therefore, the linear axisymmetric heat conduction equation for the cylinder (3) is simply converted into a linear system by using the pseudospectral Chebyshev collocation method as follows:

$$
M_{T} \boldsymbol{T}=\mathbf{0}
$$

where

$$
M_{T}=D^{2}+\left(\frac{m_{2}}{b-a}+\frac{1}{r}\right) D .
$$

Boundary conditions for temperature (11) are imposed to this linear system (12) by only replacing the first and last row of the system matrix $M_{T}$ with the appropriate values and the corresponding $R H S_{T}$ values. Then the nondimensional temperature field can be found by solving the linear system (12) by any decomposition method. After that, the linear non-homogeneous ordinary differential equation (9) in terms of dimensionless radial displacement is converted into a linear system in the following way:

$$
M_{u} \boldsymbol{u}=R(r)
$$

where

$$
M_{u}=D^{2}+P(r) D+G(r) .
$$

\section{Results and discussion}

Cylindrical components can be exposed by a variety of mechanical and thermal effects. In the present study, a hollow thick walled FG cylinder with an inner radius $a=1 \mathrm{~m}$ and outer radius $b=1.2 \mathrm{~m}$ is examined. It is presumed that the cylinder is exposed to internal pressure $P(a)=-50 \mathrm{MPa}$ and constant internal temperature $T_{w}=50^{\circ} \mathrm{C}$. The ambient temperature is set to be $T_{\infty}=25^{\circ} \mathrm{C}$. Materials are listed in Table 1 with their properties. Using the relations in Eq. (1) and the material properties in Table 1, the inhomogeneity parameters $m_{1}, m_{2}, m_{3}$ and $m_{4}$ are calculated so that the inner wall of the cylinder is pure metal and the outer wall is pure ceramic and shown in Table 2. 
M. Eker, D. Yarımpabuç

Table 1. Properties of material couples $(M C)$

\begin{tabular}{|c|c|c|c|c|c|}
\hline & Material & $E[\mathrm{GPa}]$ & $k[\mathrm{~W} / \mathrm{mK}]$ & $\alpha\left[10^{-6} \mathrm{~K}^{-1}\right]$ & $v$ \\
\hline \multirow{2}{*}{$M C_{1}$} & Silicon Nitride & 348.43 & 1.209 & 5.8723 & 0.24 \\
\cline { 2 - 6 } & Nickel & 199.5 & 90.7 & 13.30 & 0.3 \\
\hline \multirow{2}{*}{$M C_{2}$} & Mullite & 225 & 5.90 & 4.7 & 0.27 \\
\cline { 2 - 6 } & Molybdenum & 330 & 138 & 4.9 & 0.3 \\
\hline
\end{tabular}

Table 2. Inhomogeneity parameters for $M C$ 's

\begin{tabular}{|c|c|c|c|c|}
\hline & $m_{1}$ & $m_{2}$ & $m_{3}$ & $m_{4}$ \\
\hline$M C_{1}$ & 0.5576 & -4.3177 & -0.8175 & -0.2231 \\
\hline$M C_{2}$ & -0.3830 & -3.1523 & -0.0417 & -0.1054 \\
\hline
\end{tabular}

As an initial step to the analysis, grid independence tests are conducted for the cylinder and presented in Table 3. It is noted that the spectral procedure is capable of attaining $6,8,10$ digit precision by picking $11,13,15$ collocation points, respectively. Therefore, $11(N=10$ interval) collecting points are used in all analyses conducted in this study.

In addition to these analyses, the results are compared with the study of (Jabbari et al. [3]) for the same form of the FG hollow cylindrical object with the same values of material properties. The results are presented in Table 4. The compared results show that the proposed numerical solution procedure adequately provides sevendigit accuracy by using only nine collocation points.

Results of two different combinations with and thermal convection are examined graphically in Figure 1. The figure consists of four subfigures that show temperature, radial displacement, as well as radial and circumferential stresses called $a, b, c$ and $d$ respectively.

Table 3. Grid independence tests in the middle point of FG hollow cylinder wall (at $r=1.1 \mathrm{~m}$ )

\begin{tabular}{|c|c|c|}
\hline & \multicolumn{2}{|c|}{ Cylinder } \\
\hline Number of interval & $\boldsymbol{T}_{\boldsymbol{T}} \boldsymbol{T}_{\boldsymbol{w}}$ & $\boldsymbol{u}$ \\
\hline 2 & 0.9994105160 & 0.0019534844 \\
\hline 4 & 0.9992357939 & 0.0019112216 \\
\hline 6 & 0.9992524141 & 0.0019103517 \\
\hline 8 & 0.9992525121 & 0.0019103411 \\
\hline 10 & 0.9992525138 & 0.0019103410 \\
\hline 12 & 0.9992525138 & 0.0019103410 \\
\hline 14 & 0.9992525138 & 0.0019103410 \\
\hline 16 & 0.9992525138 & 0.0019103410 \\
\hline
\end{tabular}




\begin{tabular}{|c|c|c|c|c|c|c|c|c|c|c|}
\hline 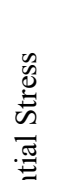 & $\begin{array}{l}\text { 离 } \\
\text { 竞 }\end{array}$ & 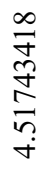 & $\begin{array}{l}\stackrel{2}{n} \\
\tilde{\sigma} \\
\cdots \\
\tilde{n} \\
\tilde{\sigma} \\
\sim\end{array}$ & $\begin{array}{l}\infty \\
\infty \\
0 \\
n \\
n \\
b \\
+ \\
\forall\end{array}$ & $\begin{array}{l}\hat{\alpha} \\
\infty \\
\hat{b} \\
0 \\
\infty \\
\dot{+}\end{array}$ & 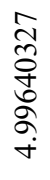 & 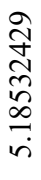 & $\begin{array}{l}\infty \\
\hat{n} \\
\widehat{N} \\
\infty \\
\infty \\
\text { m. } \\
i\end{array}$ & 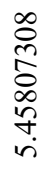 & 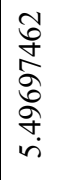 \\
\hline 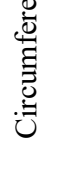 & 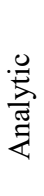 & $\begin{array}{l}\frac{\vartheta}{\vec{\sigma}} \\
\stackrel{m}{ \pm} \\
\frac{n}{\sigma}\end{array}$ & $\begin{array}{l}\hat{\tilde{n}} \\
\tilde{\sigma} \\
\tilde{n} \\
\tilde{n} \\
\tilde{\sigma}\end{array}$ & $\begin{array}{l}2 \\
0 \\
0 \\
n \\
n \\
0 \\
\dot{\gamma}\end{array}$ & 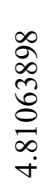 & 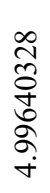 & $\begin{array}{l}\overrightarrow{3} \\
\underset{N}{N} \\
\tilde{n} \\
\infty \\
\vec{H}\end{array}$ & 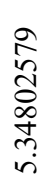 & 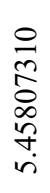 & 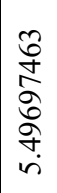 \\
\hline 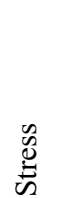 & 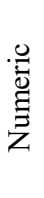 & $\begin{array}{l}8 \\
8 \\
0 \\
0 \\
0 \\
8 \\
\\
i\end{array}$ & 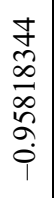 & 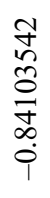 & 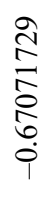 & 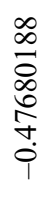 & 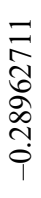 & $\begin{array}{l}\overrightarrow{1} \\
\infty \\
0 \\
0 \\
n \\
0 \\
0\end{array}$ & 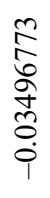 & $\begin{array}{l}8 \\
8 \\
8 \\
8 \\
8 \\
8 \\
0 \\
0\end{array}$ \\
\hline 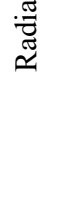 & 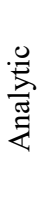 & $\begin{array}{l}8 \\
8 \\
0 \\
0 \\
0 \\
0 \\
i \\
i\end{array}$ & 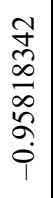 & 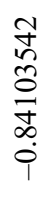 & 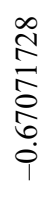 & 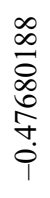 & 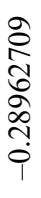 & 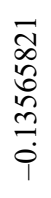 & 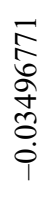 & $\begin{array}{l}8 \\
8 \\
8 \\
8 \\
8 \\
0 \\
0\end{array}$ \\
\hline 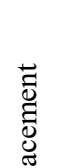 & 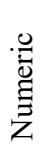 & 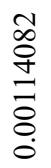 & 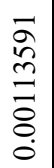 & 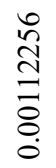 & $\begin{array}{l}\frac{n}{8} \\
\stackrel{0}{0} \\
\overline{8} \\
\stackrel{0}{0}\end{array}$ & 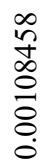 & $\begin{array}{l}\frac{8}{8} \\
\frac{8}{8} \\
\frac{0}{8} \\
\stackrel{0}{0}\end{array}$ & $\begin{array}{l}\frac{J}{2} \\
\text { ñ } \\
0 \\
8 \\
0 \\
0\end{array}$ & $\begin{array}{l}\frac{2}{2} \\
\frac{d}{0} \\
\frac{8}{8} \\
\dot{0}\end{array}$ & $\begin{array}{l}\frac{1}{2} \\
\text { I } \\
0 \\
0 \\
0 \\
0 \\
0\end{array}$ \\
\hline 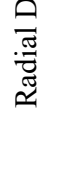 & 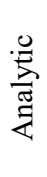 & 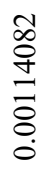 & $\begin{array}{l}\bar{\sigma} \\
\text { ñ } \\
\bar{\Xi} \\
\overline{8} \\
\dot{0}\end{array}$ & 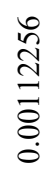 & $\begin{array}{l}\frac{i}{\sigma} \\
0 \\
\Xi \\
\overline{8} \\
\dot{0}\end{array}$ & 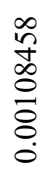 & $\begin{array}{l}8 \\
\frac{8}{8} \\
\frac{1}{8} \\
\stackrel{0}{0} \\
\stackrel{0}{0}\end{array}$ & $\begin{array}{l}\frac{7}{5} \\
\hat{n} \\
0 \\
8 \\
0\end{array}$ & $\begin{array}{l}\frac{2}{\partial} \\
\frac{8}{0} \\
\stackrel{8}{8} \\
\dot{0}\end{array}$ & $\begin{array}{l}\frac{1}{2} \\
\frac{1}{0} \\
0 \\
8 \\
0 \\
0\end{array}$ \\
\hline 节 & $\begin{array}{l}\cdot \stackrel{\circlearrowright}{\mathbb{d}} \\
\Xi \\
\text { Z }\end{array}$ & $\begin{array}{l}8 \\
8 \\
8 \\
8 \\
8 \\
8 \\
\end{array}$ & $\begin{array}{l}\infty \\
\infty \\
\infty \\
\hat{o} \\
\hat{n} \\
\vdots \\
0\end{array}$ & 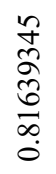 & 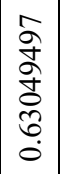 & 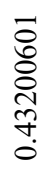 & 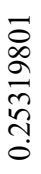 & $\begin{array}{l}\stackrel{8}{0} \\
\stackrel{+}{+} \\
\stackrel{n}{n} \\
= \\
\end{array}$ & 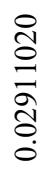 & $\begin{array}{l}8 \\
8 \\
8 \\
8 \\
8 \\
8 \\
0 \\
0 \\
0\end{array}$ \\
\hline$\underset{\Xi}{\overrightarrow{0}}$ & 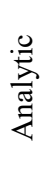 & $\begin{array}{l}8 \\
8 \\
8 \\
8 \\
8 \\
8 \\
-\end{array}$ & $\begin{array}{l}\hat{\infty} \\
\infty \\
\tilde{n} \\
0 \\
\tilde{n} \\
0\end{array}$ & $\begin{array}{c}n \\
\tilde{\sigma} \\
\hat{\sigma} \\
\tilde{\sigma} \\
\infty \\
0 \\
0\end{array}$ & 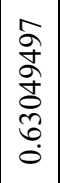 & 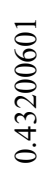 & 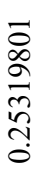 & $\begin{array}{l}\stackrel{8}{0} \\
\stackrel{1}{*} \\
\stackrel{n}{n} \\
\exists \\
\end{array}$ & 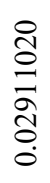 & $\begin{array}{l}8 \\
8 \\
8 \\
8 \\
8 \\
0 \\
0\end{array}$ \\
\hline & 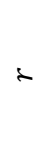 & $\begin{array}{l}8 \\
8 \\
8 \\
8 \\
8 \\
\end{array}$ & $\begin{array}{l}\frac{1}{\sigma} \\
\frac{8}{8} \\
\frac{8}{-}\end{array}$ & 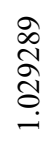 & $\frac{N}{\stackrel{2}{0}}$ & $\begin{array}{l}8 \\
8 \\
8 \\
\circ \\
\stackrel{0}{0}\end{array}$ & 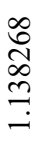 & $\begin{array}{l}\text { 三 } \\
\text { 을 } \\
\stackrel{-}{-}\end{array}$ & 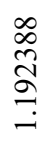 & $\begin{array}{l}8 \\
8 \\
8 \\
\text { ㄱ. }\end{array}$ \\
\hline
\end{tabular}


The effect of two different material pairs, $M C_{1}, M C_{2}$ on a hollow FG cylinder is monitored in Figure 1. Due to the lower ambient temperature and convective boundary conditions, the temperature of the outer surface is lower compared to the inner surface (Fig. 1a). $M C_{1}$ reaches a lower temperature value than $M C_{2}$ at the outer radius in Figure 1a. Its clearly seen from Figure $1 \mathrm{~b}$ that lower radial displacement occurs in $M C_{2}$. This is the result of choosing the inhomogeneity parameter as negative for the Young's modulus in the grading of $M C_{2}$. It is also due to the choice of Young's modulus closer to each other and relatively higher in grading material used in pairs.

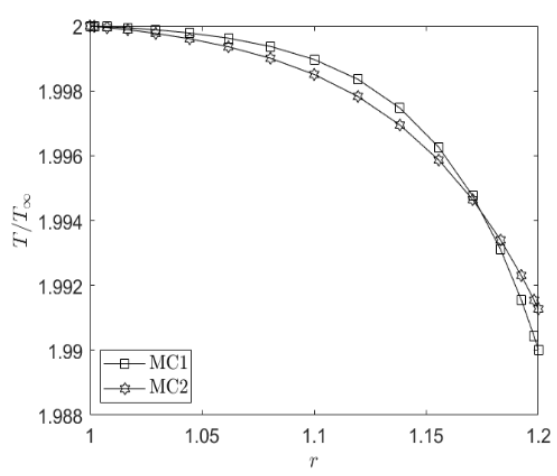

(a) Temperature

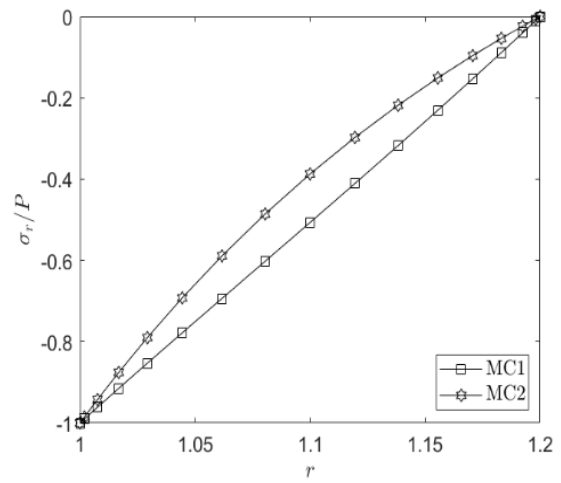

(c) Radial stress distribution

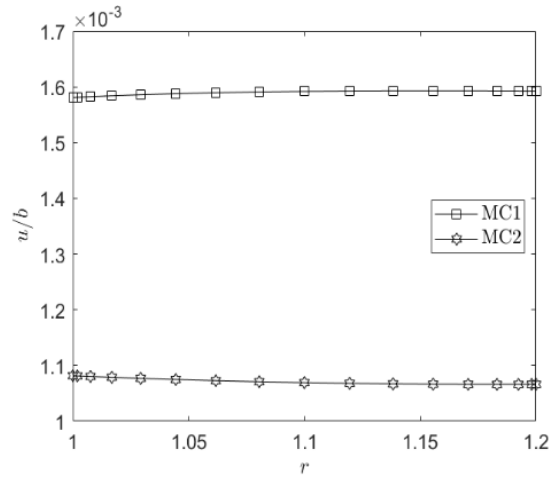

(b) Radial displacement

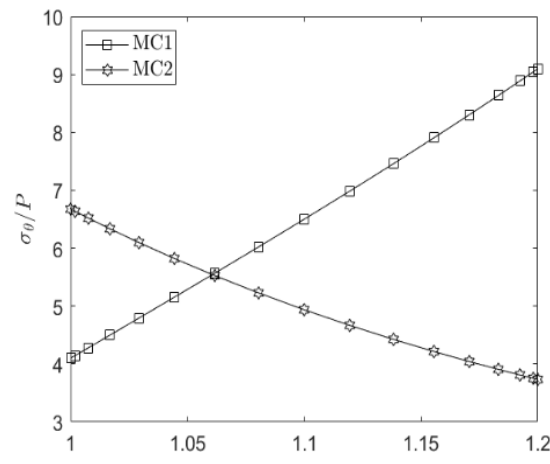

(d) Circumferential stress distribution

Fig. 1. The dimensionless temperature, radial displacement, and radial and circumferential stress distributions of hollow FGM cylinder for materials $M C_{1}$ and $M C_{2}$

In Figure 1c, radial stress in the direction of compression and $M C_{2}$ has lower values than $M C_{1}$ in any point of wall thickness. On the outer radius, radial stress reduces to zero due to the traction free boundary condition. Although the circumferential stress is lower for $M C_{1}$ in the inner wall, it reverses on the outer wall, and $M C_{2}$ reaches lower stress value. Both $M C s$ meet the same circumferential stress value around the wall midpoint. It can be concluded that $M C_{2}$ is relatively suitable due to keeping circumferential stress stable along the wall thickness. 


\section{Conclusions}

In this study, thermal and mechanical stresses in a hollow thick-walled cylinder made of FGM under the effect of thermal convection coefficient is presented. All material properties are assumed to vary exponentially in the radial direction. These inhomogeneous material properties produce an irregular and variable coefficient two-point linear boundary value problem. This linear boundary value problem is solved numerically by the pseudospectral Chebyshev method. Benchmark solutions are used to verify the temperature, displacement and stress distributions in the form of tables. Results agree with the study of Jabbari et al. [3]. Furthermore, grid independence tests are conducted to emphasize the convergence of the numerical solutions. In the analysis, two different ceramic and metal mixtures are used as special materials. The effect of the two different mixtures and thermal convection on temperature, displacement and stresses are discussed extensively. In addition, the pseudospectral Chebyshev method used in this study, based on the definition of spatial fields using Chebyshev polynomials with grid density at the boundaries, is a method in which derivatives are calculated with high accuracy using very few collocation points. Therefore, this method has high accuracy, low calculation costs and ease of application and can be easily adapted to such engineering problems.

\section{References}

[1] Bezzie, Y.M., \& Woldemichael, D.E. (2021). Effects of graded-index and Poisson's ratio on elastic-solutions of a pressurized functionally graded material thick-walled cylinder. Forces in Mechanics, 4, 100032.

[2] Obata, Y., \& Noda, N. (1994). Steady thermal stresses in a hollow circular cylinder and a hollow sphere of a functionally gradient material. Journal of Thermal Stresses, 17(3), 471-487.

[3] Jabbari, M., Sohrabpour, S., \& Eslami, M.R. (2002). Mechanical and thermal stresses in a functionally graded hollow cylinder due to radially symmetric loads. International Journal of Pressure Vessels and Piping, 79(7), 493-497.

[4] Liew, K.M., Kitipornchai, S., Zhang, X.Z., \& Lim, C.W. (2003). Analysis of the thermal stress behaviour of functionally graded hollow circular cylinders. International Journal of Solids and Structures, 40(10), 2355-2380.

[5] Jabbari, M., Bahtui, A., \& Eslami, M.R. (2006). Axisymmetric mechanical and thermal stresses in thick long FGM cylinders. Journal of Thermal Stresses, 29(7), 643-663.

[6] Peng, X.L., \& Li, X.F. (2010). Thermoelastic analysis of a cylindrical vessel of functionally graded materials. International Journal of Pressure Vessels and Piping, 87(5), 203-210.

[7] Ostrowski, P., \& Michalak, B. (2011). Non-stationary heat transfer in hollow cylinder with functionally graded material properties. Journal of Theoretical and Applied Mechanics, 49(2), 385-397.

[8] Alashti, R.A., Khorsand, M., \& Tarahhomi, M.H. (2013). Three-dimensional asymmetric thermoelastic analysis of a functionally graded rotating cylindrical shell. Journal of Theoretical and Applied Mechanics, 51(1), 143-158.

[9] Xin, L., Yang, S., Ma, B., \& Dui, G. (2015). Thermoelastic analysis of a functionally graded rotating thick-walled tube subjected to mechanical and thermal loads. International Journal of Thermophysics, 36(10-11), 3017-3036. 
[10] Seifi, R. (2015). Exact and approximate solutions of thermoelastic stresses in functionally graded cylinders. Journal of Thermal Stresses, 38(10), 1163-1182.

[11] Celebi, K., Yarimpabuc, D., \& Keles, I. (2017). A novel approach to thermal and mechanical stresses in a FGM cylinder with exponentially varying properties. Journal of Theoretical and Applied Mechanics, 55(1), 343-351.

[12] Benslimane, A., Benchallal, R., Mammeri, S., Methia, M., \& Khadimallah, M.A. (2020). Investigation of displacements and stresses in thick-walled FGM cylinder subjected to thermo-mechanical loadings. International Journal for Computational Methods in Engineering Science and Mechanics, 22(2), 138-149.

[13] Chen, Y.Z. (2021). A novel numerical solution for a functionally graded hollow cylinder with arbitrary elastic property along the radial direction. International Journal of Pressure Vessels and Piping, 191, 104301.

[14] Bezzie, Y.M., \& Woldemichael, D.E. (2021). Effects of graded-index and Poisson's ratio on elastic-solutions of a pressurized functionally graded material thick-walled cylinder. Forces in Mechanics, 100032 .

[15] Trefethen, L.N. (2000). Spectral Methods in Matlab, 10, SIAM, Philadelphia, PA.

[16] Fornberg, B. (1998). A Practical Guide to Pseudospectral Methods, 1. Cambridge: Cambridge University Press.

[17] Bazan, F.S.V. (2008). Chebyshev Pseudospectral Method for Computing Numerical Solution of Convection-Diffusion Equation. Applied Mathematics and Computation, 200(2), 537-546.

[18] Hahn, W.D., \& Ozisik, M.N. (2012). Heat Conduction, New Jersey: John Wiley Sons.

[19] Gottlieb, D. (1981). The stability of pseudospectral-Chebyshev methods. Mathematics of Computation, 36(153), 107-118. 